\title{
Identification of Circulating MiR-25 as a Potential Biomarker for Pancreatic Cancer Diagnosis
}

\author{
Ting Deng $^{\mathrm{a}}$ Yaozong Yuan ${ }^{\mathrm{b}}$ Chunni Zhang ${ }^{\mathrm{c}}$ Chenyu Zhang ${ }^{\mathrm{d}}$ Weiyan Yao ${ }^{\mathrm{b}}$ \\ Cheng Wang ${ }^{c}$ Rui Liu ${ }^{a}$ Yi Ba ${ }^{a}$
}

\begin{abstract}
aDepartment of Gastrointestinal Medical Oncology, Tianjin Medical University Cancer Institute and Hospital; National Clinical Research Center of Cancer; Key Laboratory of Cancer Prevention and Therapy of Tianjin, Tianjin, bepartment of Gastroenterology, Ruijin Hospital, Shanghai Jiaotong University School of Medicine, Shanghai, 'Department of Clinical Laboratory, Jinling Hospital, Clinical School of Medical College, Nanjing University, Nanjing, dJiangsu Engineering Research Center for microRNA Biology and Biotechnology, State Key Laboratory of Pharmaceutical Biotechnology, School of Life Sciences, Nanjing University, Nanjing, China
\end{abstract}

\section{Key Words}

MiR-25 • Pancreatic cancer $\bullet$ Serum $\bullet$ Biomarker $\bullet$ Circulating microRNAs

\begin{abstract}
Background: The aim of this study was to identify novel microRNAs for potential use in the diagnosis of pancreatic cancer ( $\mathrm{PaC}$ ). Methods: A total of 1063 serum samples from 303 patients with $\mathrm{PaC}$ were collected, and the expression level of miR-25 was measured using quantitative real-time PCR (qRT-PCR). Results: We found that miR-25 had significant diagnostic value for the differential diagnosis of $\mathrm{PaC}$ in normal controls with an AUC (the area under the ROC curve) of 0.915 (95\% CI: 0.893-0.937) that was significantly higher compared with an AUC of 0.725 for serum tumor marker carcinoembryonic antigen (CEA) and an AUC of 0.844 for CA19-9. Conclusions: These data suggest that serum miR-25 has strong potential as a novel biomarker for the early detection of PaC.

\section{Introduction}

Pancreatic cancer $(\mathrm{PaC})$ is the fourth leading cause of cancer-related deaths with the poorest survival rate (less than 5\%) among common malignancies [1,2]. Early diagnosis of $\mathrm{PaC}$ is still difficult, and currently, no credible blood biomarkers exist to help identify patients with $\mathrm{PaC}$ at an early stage [3, 4]. Because of a lack of timely diagnosis, only approximately $20 \%$ of patients with $\mathrm{PaC}$ can undergo surgical treatment with curative intent, and the remaining cases have locally advanced or metastatic $\mathrm{PaC}$ at the time of diagnosis [3]. Therefore, it is




\section{Cellular Physiology Cell Physiol Biochem 2016;39:1716-1722

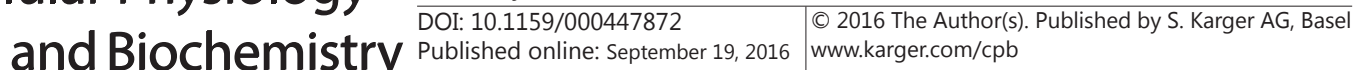 \\ Deng et al.: MiR-25 for Pancreatic Cancer Diagnosis}

critical to identify specific biomarkers for the early diagnosis of $\mathrm{PaC}$, especially for earlystage malignant tumors.

MicroRNAs (miRNAs) are single-stranded RNA molecules of approximately 22 nucleotides (nt) long comprising noncoding RNAs that function as repressors of gene expression, particularly as posttranscriptional repressors. MicroRNAs have been shown to play important roles in oncogenesis and tumor metastasis. Studies involving miRNAs have been expanded to various categories for malignant tumors, including $\mathrm{PaC}[5,6]$, suggesting that miRNAs might be potential biomarkers for the diagnosis and prognosis of cancer. Diagnostic biomarkers from the blood could be valuable because it is difficult to obtain useful tissue biopsies from patients suspected of having PaC. Retrospective studies have shown that expression of specific miRNAs in the plasma or serum can distinguish patients with PaC from healthy controls [7-9].

miR-25 is one of the most studied and well-described miRNAs related to human disorders including cancer. It is transcribed from the minichromosome maintenance protein-7 (MCM7) gene and is $22 \mathrm{nt}$ long. It is overexpressed in various human carcinomas including brain tumors, gastric adenocarcinoma, prostate carcinoma, and ovarian cancer $[10,11]$. A previous study carried out by our group used a genome-wide miRNA expression profile in serum from $197 \mathrm{PaC}$ patients and 158 cancer-free controls and indicated that miR25 was overexpressed in $\mathrm{PaC}$ patients; therefore, it might be a potential biomarker for the diagnosis of PaC [9]. However, a group of miRNAs was screened in this study; however, it would be more convenient and less expensive if we could screen for one miRNA with the most potential. Furthermore, more clinical samples are needed to further characterize the role of miR-25 for the diagnosis of PaC. In the present study, PaC patients, controls with other diseases, and normal controls (cancer-free) were recruited to investigate whether miR-25 was potent enough to be a biomarker for the diagnosis of $\mathrm{PaC}$.

\section{Patients and Methods}

\section{Patient selection}

A total of 1063 serum samples from PaC patients or control participants admitted to three national hospitals were collected. The samples from PaC patients met the following criteria: a) PaC diagnosis confirmed by pathological examination; b) no acute infection; c) no jaundice; and d) alanine aminotransferase (ALT) and aspartate aminotransferase (AST) levels less than 2.5 times the upper limit of normal (ULN). This project was approved by the Clinical Research Ethics Committee of all three hospitals.

\section{Sample processing and RNA extraction}

All serum samples were recovered and kept at $-80^{\circ} \mathrm{C}$ until analysis. The total RNA was extracted from $100 \mu \mathrm{l}$ of serum through phenol/chloroform purification followed by centrifugation in isopropyl alcohol. Because U6 and 5S rRNAs were degraded in the serum samples and because there is no current consensus on housekeeping miRNAs for a qRT-PCR analysis of serum miRNAs, the expression levels of miRNAs were directly normalized to the serum volume in this study. Briefly, $2 \mu \mathrm{l}$ of total RNA was reverse-transcribed to cDNA using an AMV reverse transcriptase (Takara, Dalian, China) and a stem-loop RT primer (Applied Biosystems, Foster City, CA, USA).

\section{miRNA quantification by qRT-PCR}

Hydrolysis probes (Applied Biosystems, Foster City, CA, USA) were used for the qRT-PCR analysis; this system is highly specific for the target miRNA, but not for longer pre-processed precursors or other highly homologous miRNAs, which differ in sequence by as little as one nucleotide [12, 13]. qRT-PCR was performed using a TaqMan PCR kit on an Applied Biosystems 7300 Sequence Detection System (Applied Biosystems, Foster City, CA, USA). All reactions were run in triplicate. After the reaction, the $\mathrm{C}_{\mathrm{T}}$ values were determined based on fixed threshold settings. The experimenters were blinded to the identities of the cases and controls, and samples from cases and controls were mixed on the qRT-PCR plates to avoid batch effects. 


\section{Cellular Physiology Cell Physiol Biochem 2016;39:1716-1722 \\ and Biochemistry Published \begin{tabular}{l|l} 
(c) 2016 The Author(s). Published by S. Karger AG, Basel \\
DOI: 10.1159/000447872
\end{tabular} \\ Deng et al: MiR-25 for Pancreatic Cancer Diagnosis}

Statistical analysis

Expression levels of serum miRNAs were compared using Student's t-test. Receiver operator characteristic (ROC) curves were established to evaluate the diagnostic value of serum miRNAs for differentiating cancer patients from controls. A $p$ value of less than 0.05 and $Z$ value of more than 1.96 were considered significant. All statistical analyses were performed with SPSS 18.0 software (SPSS Inc, Chicago, IL). The classified points can be divided into four categories: true positives $(T P)$, true negatives $(T N)$, false positives $(F P)$, and false negatives $(F N)$.

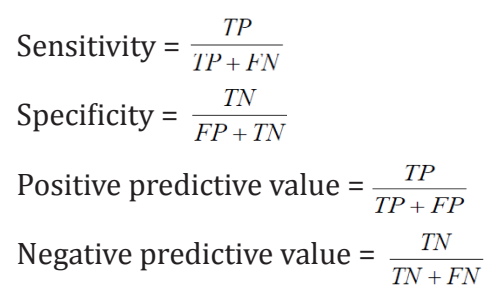

\section{Results}

\section{Patient characteristics}

Clinical characteristics of the study participants are presented in Table 1. A total of 600 samples were collected from normal controls (cancer-free), 160 samples from patients with other diseases (including 40 with chronic pancreatitis, 20 with gastric cancer, 20 with lung cancer, 20 with esophageal cancer, 20 with colorectal cancer, 20 with liver cancer, and 20 with breast cancer), and 303 samples from patients with PaC. For patients with PaC, the $\mathrm{PaC}$ was confirmed by a pathological diagnosis. Because of restrictions in obtaining samples from the participants, there was a significant difference in age between normal controls and $\mathrm{PaC}$ patients, as well as controls with other diseases and PaC patients (both $p<0.0001$ ).

CA19-9 and CEA for the diagnosis of $\mathrm{PaC}$

The expression levels of carbohydrate antigen 19-9 (CA19-9) and carcinoembryonic antigen (CEA) in PaC patients and those with other diseases were quantitatively measured and statistically compared (Table 2). CA19-9 was measured in $288 \mathrm{PaC}$ patients with different stages of cancer, and $72.9 \%$ of them were positi-
Table 1. Demographic and clinical characteristics of patients and controls

\begin{tabular}{lccc}
\hline Variable & Normal control & Other disease Control & $\mathrm{PaC}$ \\
\hline No. of cases & 600 & 160 & 303 \\
Age (mean \pm SD) & $49 \pm 16$ & $56 \pm 13$ & $62 \pm 10$ \\
Sex & & & \\
Male & 359 & 102 & 188 \\
Female & 241 & 58 & 115 \\
Stage(TNM) & & & \\
I & & & $9(2.97 \%)$ \\
II & & $39(12.87 \%)$ \\
III & & $47(15.51 \%)$ \\
IV & & $123(40.59 \%)$ \\
Unknown & & & $85(28.05 \%)$ \\
\hline
\end{tabular}

Table 2. Positive ratio for known serum biomakers CA19-9 and CEA. *: The cut-off values for CA19-9 and CEA were $39 \mathrm{kU} / \mathrm{L}$ and $5 \mu \mathrm{g} / \mathrm{L}$, respectively

\begin{tabular}{lllll}
\hline & \multicolumn{2}{c}{ CA19-9 } & \multicolumn{2}{c}{ CEA } \\
\hline Classification & No. of positive & Positive & No. of positive & Positive \\
& cases/total cases & ratio(\%) & cases/total cases & ratio(\%) \\
Stage I & $6 / 9$ & 66.67 & $3 / 9$ & 33.33 \\
II & $27 / 39$ & 69.23 & $9 / 39$ & 23.08 \\
III & $31 / 46$ & 67.39 & $14 / 44$ & 31.82 \\
IV & $88 / 119$ & 73.95 & $71 / 119$ & 59.66 \\
PaC case in total & $210 / 288$ & 72.92 & $134 / 281$ & 47.69 \\
Other diseases case & $32 / 117$ & 27.35 & $30 / 125$ & 24.00 \\
\hline
\end{tabular}




\section{Cellular Physiology Cell Physiol Biochem 2016;39:1716-1722 \begin{tabular}{ll|l} 
and BiOChemistry & $\begin{array}{l}\text { DOI: 10.1159/000447872 } \\
\text { Published online: September 19, } 2016\end{array}$ & $\begin{array}{l}\text { C } 2016 \text { The Author(s). Published by S. Karger AG, Basel } \\
\text { www.karger.com/cpb }\end{array}$ \\
\hline
\end{tabular}

ve (above the $39 \mathrm{kU} / \mathrm{l}$-cutoff level), whereas $27.4 \%$ of the patients with other diseases were also positive for CA19-9. However, the positive percentage of CEA was only $47.7 \%$ with a high false-positive rate of $24.0 \%$ in $281 \mathrm{PaC}$ patients and 125 controls. These results demonstrated a false-positive rate of $<50 \%$ and $24 \%$ for CA19-9 and CEA, respectively.

Expression level of miR-25 in PaC patients The serum miR-25 expression level was detected with qRT-PCR. Expression miRNA levels were expressed as copies/ $\mu \mathrm{l}$ of serum. The cutoff value for miR-25 was 20,000 copies/ $\mu$ l. As shown in Figure 1 , the median concentration of miR-25 was 8391.82, 10377.70, and 45659.24 copies/ $\mu \mathrm{l}$ for normal controls, patients with other diseases, and $\mathrm{PaC}$ patients, respectively. These results revealed that miR-25 expression was significantly upregulated in $\mathrm{PaC}$ patients compared with that of normal controls and patients with other diseases (both $p<0.0001$ ) (Fig.1).

The distribution of miR-25 in $\mathrm{PaC}$ patients was also studied (Table 3). In the $303 \mathrm{PaC}$ patients, 74 (24.42\%), 150 (49.51\%), and $79(26.07 \%)$ of the cases were negative, weak positive, and strong positive, respectively, for miR-25. Overall, 229 (75.58\%) of $\mathrm{PaC}$ patients were positive for miR-25; this percentage was comparable to that of CA19-9 (72.9\%) but was significantly higher than that of CEA $(47.7 \%)(p<0.0001)$. The sensitivity was calculated as $75.58 \%$, and the specificity was $93.03 \%$. The positive predictive value was $81.21 \%$, and the negative predictive value was $90.52 \%$, indicating that miR-25 had a strong potential as a biomarker for the early diagnosis of PaC.

\section{ROC curve of miR-25 in PaC patients}

An ROC curve analysis illustrated the use of serum miR-25 in the differential diagnosis of PaC (Fig. 2). Significance was noted between CEA and CA19-9, but no overlap was noted among miR-25, CEA, and CA19-9 ( $p<0.05$ and $Z>1.96)$, as illustrated in Table 4. Serum miR-25 yielded an AUC of 0.915 (95\% CI: 0.893-0.937). At a cutoff value of 20,000 copies/ $\mu$ l, the sensitivity and specificity of miR-25 were detected to be $75.58 \%$ and $93.03 \%$, respectively. As shown

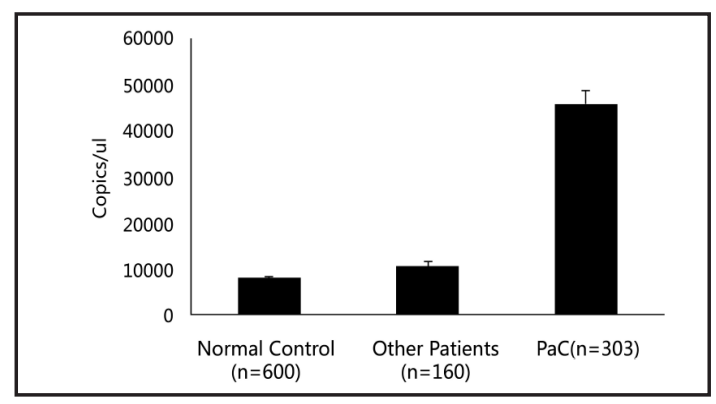

Fig. 1. Expression of miR-25 in serum samples. The histogram showing serum levels of miR-25 in healthy subjects $(n=600)$, other diseases $(n=160)$, and $\mathrm{PaC}$ patients $(\mathrm{n}=303)$. Expression levels of miRNA are shown as copies/ $\mu$ l. A Mann-Whitney U test was used to determine significance.

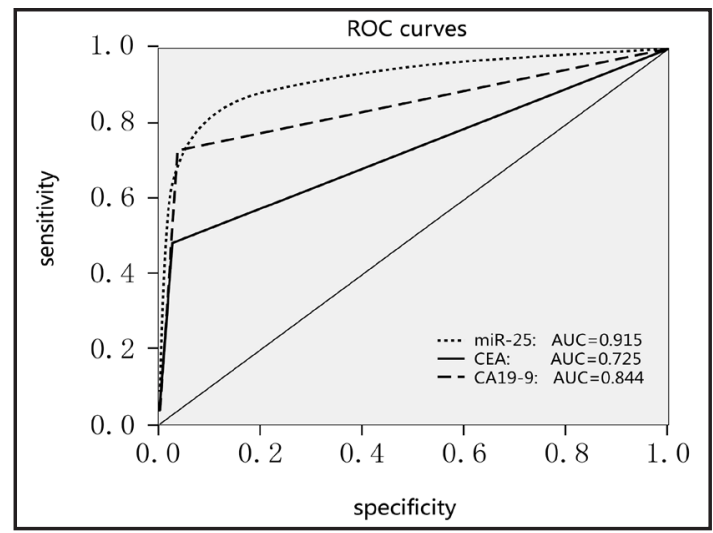

Fig. 2. Receiver operating characteristics (ROC) curve analysis using serum miR-25 for discriminating pancreatic cancer. Serum miR-25 yielded an AUC (area under the ROC curve) of 0.915 (95\% CI: 0.893-0.937), while known serum biomarkers CEA and CA19-9 yielded an AUC of only 0.725 (95\% CI: $0.685-0.765$ ) and 0.844 (95\% CI: 0.811-0.876), respectively.

Table 3. Distribution of miR-25 in $\mathrm{PaC}$ patients $(n=303)$. *Standards for classification: negative, $\leq 20,000$ copies/ $\mu$ l; weak positive, between 20,000 to 50,000 copies/ $\mu$ l; strong positive, $\geq 50,000$ copies $/ \mu \mathrm{l}$

\begin{tabular}{lcc}
\hline Classification* & No. of cases & proportion \\
\hline Negative & 74 & $24.42 \%$ \\
Weak positive & 150 & $49.51 \%$ \\
Strong positive & 79 & $26.07 \%$ \\
\hline
\end{tabular}

Table 4. Significant differences in the AUC between miR-25 and CEA/CA19-9

\begin{tabular}{lcc}
\hline $\begin{array}{l}\text { Significant } \\
\text { difference }\end{array}$ & miR-25 vs. CEA & miR-25 vs. CA19-9 \\
\hline $\mathrm{Z}$ & 6.7304 & 3.5392 \\
$\mathrm{P}$ & $<0.000001$ & 0.000402 \\
\hline
\end{tabular}




\section{Cellular Physiology Cell Physiol Biochem 2016;39:1716-1722 \\ \begin{tabular}{l|l|l} 
and Biochemistry Published online: September 19, 2016 & $\begin{array}{l}\text { (c) } 2016 \text { The Author(s). Published by S. Karger AG, Basel } \\
\text { www.karger.com/cpb }\end{array}$ \\
\hline
\end{tabular} \\ Deng et al.: MiR-25 for Pancreatic Cancer Diagnosis}

in Figure 2, the AUC was 0.725 (95\% CI: 0.685-0.765) for CEA and 0.844 (95\% CI: 0.811 0.876 ) for CA19-9 and was significantly lower as compared with an AUC of 0.915 (95\% CI: 0.893-0.937) for serum miR-25.

\section{Discussion}

miRNAs have been proven to serve as potential diagnostic biomarkers and prognostic factors in different types of cancers [14-18]. Meanwhile, miRNAs play a vital role in the pathogenesis, progression, and metastasis of $\mathrm{PaC}$ [19-24]. Serum miRNAs have been suggested as a biomarker for the diagnosis of PaC. The differential expression levels of miRNAs have been associated with the survival of PaC patients $[25,26]$. In the search of novel biomarkers for PaC, Wang et al. described a combined analysis of the expression levels of four plasma miRNAs including miR-21, miR-210, miR-155, and miR-196a that have been known to be overexpressed in PaC tissues and were used as biomarkers to diagnose and differentiate patients with pancreatic adenocarcinoma from healthy controls with a relatively high sensitivity of $64 \%$ and specificity of $89 \%$ [7]. Circulating miRNAs combined with the serum marker CA19-9 has been used in the clinical diagnosis of $\mathrm{PaC}$ [8]. Ho et al. statistically compared the expression levels of miR-210 in plasma samples from patients diagnosed with $\mathrm{PaC}$ and age-matched healthy controls [27]. Dai et al. [28] selected a panel of six serum miRNAs including miR-483-5p, miR-19a, miR-29a, miR-20a, miR-24, and miR-25, and a qRT-PCR analysis demonstrated that the six-serum miRNA panel acted as potential biomarkers for the accurate diagnosis and discrimination of $\mathrm{PaC}$ from healthy controls and non-cancer T2DM.

CA19-9, which is significantly upregulated in approximately $80 \%$ of patients diagnosed with $\mathrm{PaC}$, has been regarded as a useful biomarker for the diagnosis of $\mathrm{PaC}$ [3]. Moreover, CA19-9 has been used to estimate the therapeutic efficacy and clinical prognosis of patients with PaC [29]. CEA is commonly used as a serum biomarker in colorectal and PaC as part of preoperative staging and postoperative follow-up for clinical response in patients selected for treatment [30]. Therefore, the serum levels of CA19-9 and CEA were quantitatively measured and statistically compared with the expression of miR-25 in this investigation.

In our previous investigation [9], researchers from our study group screened multiple miRNAs in 197 patients diagnosed with $\mathrm{PaC}$ and 158 cancer-free controls and demonstrated that miR-25 is one of the most significantly upregulated miRNAs in PaC patients. In this large sample size study, a total of 1063 participants including 303 patients with $\mathrm{PaC}$ were recruited that further confirm that miR-25 serves as a biomarker for the diagnosis of $\mathrm{PaC}$ with a relatively high sensitivity and specificity. In addition to the cancer-free normal controls, 160 patients with other diseases such as chronic pancreatitis, gastric cancer, lung cancer, esophagus cancer, colorectal cancer, liver cancer, and breast cancer were enrolled in equal numbers and were used to investigate whether miR-25 was specific to PaC or only elevated in cancer patients. The results unambiguously showed that miR-25 could be used to not only distinguish $\mathrm{PaC}$ from healthy individuals, but also differentially diagnose $\mathrm{PaC}$ from alternative diseases.

The ROC curve analysis also confirmed that serum miR-25 levels could help differentiate patients with $\mathrm{PaC}$ from healthy controls; help determine a PaC diagnosis, with an AUC of 0.915 (95\% CI: 0.893-0.937); and were significantly higher, as compared with an AUC of 0.725 (95\% CI: $0.685-0.765$ ) for CEA and 0.844 (95\% CI: 0.811-0.876) for CA19-9. In the current study, the sensitivity of miR-25 for the diagnosis of PaC was comparable to that of CA19-9 (73\%) and significantly higher than CEA (48\%). The false-positive rate for miR-25 was as low as $8 \%$ that was considerably lower than CA19-9 (27\%) and CEA (24\%). These results suggested that miR-25 is a better biomarker for the diagnosis of $\mathrm{PaC}$ with a higher sensitivity and specificity than well-known serum biomarkers.

Healthy individuals of differing ages were recruited for this investigation. An older age was consistently correlated with the incidence of PaC. Previous studies have demonstrated 


\section{Cellular Physiology Cell Physiol Biochem 2016;39:1716-1722 \begin{tabular}{l|l|l} 
and Biochemistry Published online: September 19, 2016 & $\begin{array}{l}\text { C } 2016 \text { The Author(s). Published by S. Karger AG, Basel } \\
\text { www.karger.com/cpb }\end{array}$
\end{tabular} \\ Deng et al.: MiR-25 for Pancreatic Cancer Diagnosis}

no association between age and miRNA expression in both study cases and healthy controls [5]. However, other investigations have suggested that serum miRNA expression is likely to be affected by aging [31]. In this study, it was more specific and accurate to evaluate the role of miR-25 in normal controls of differing ages.

\section{Conclusion}

In this large-sample investigation, 303 patients with $\mathrm{PaC}$ and 760 controls were recruited from three national hospital centers to help guarantee the accuracy and objectivity of the study findings. The findings in this investigation have demonstrated that miR-25 could be considered a novel biomarker for the diagnosis of $\mathrm{PaC}$ with sensitivity and accuracy comparable to those of CA19-9 but higher than those of CEA.

\section{Acknowledgements}

Our paper was financially supported by the National Natural Science Foundation of China (No.81372394), National Science and Technology Major Project (No.2013ZX09303001).

\section{Disclosure Statement}

None declared.

\section{References}

1 Siegel R, Naishadham D, Jemal A: Cancer statistics, 2013. CA Cancer J Clin 2013;63:11-30.

2 Ferlay J, Steliarova-Foucher E, Lortet-Tieulent J, Rosso S, Coebergh JW, Comber H, Forman D, Bray F: Cancer incidence and mortality patterns in Europe: estimates for 40 countries in 2012. Eur J Cancer 2013;49:1374-1403.

3 Hidalgo M: Pancreatic cancer. N Engl J Med 2010;362:1605-1617.

4 Locker GY, Hamilton S, Harris J, Jessup JM, Kemeny N, Macdonald JS, Somerfield MR, Hayes DF, Bast RC Jr: ASCO 2006 update of recommendations for the use of tumor markers in gastrointestinal cancer. J Clin Oncol 2006;24:5313-5327.

5 Schultz NA, Dehlendorff C, Jensen BV, Bjerregaard JK, Nielsen KR, Bojesen SE, Calatayud D, Nielsen SE, Yilmaz M, Holländer NH, Andersen KK, Johansen JS: MicroRNA biomarkers in whole blood for detection of pancreatic cancer. JAMA 2014;311:392-404.

6 Buchsbaum DJ, Croce CM: Will detection of microRNA biomarkers in blood improve the diagnosis and survival of patients with pancreatic cancer? JAMA 2014;311:363-365.

7 Wang J, Chen J, Chang P, LeBlanc A, Li D, Abbruzzesse JL, Frazier ML, Killary AM, Sen S: MicroRNAs in plasma of pancreatic ductal adenocarcinoma patients as novel blood-based biomarkers of disease. Cancer Prev Res (Phila) 2009;2:807-813.

8 Liu J, Gao J, Du Y, Li Z, Ren Y, Gu J, Wang X, Gong Y, Wang W, Kong X: Combination of plasma microRNAs with serum CA19-9 for early detection of pancreatic cancer. Int J Cancer 2012;131:683-691.

9 Liu R, Chen X, Du Y, Yao W, Shen L, Wang C, Hu Z, Zhuang R, Ning G, Zhang C, Yuan Y, Li Z, Zen K, Ba Y, Zhang CY: Serum microRNA expression profile as a biomarker in the diagnosis and prognosis of pancreatic cancer. Clin Chem 2012;58:610-618.

10 Marchi S, Pinton P: Mitochondrial calcium uniporter, MiRNA and cancer: Live and let die. Commun Integr Biol 2013;6:e23818.

11 Zhang H, Zuo Z, Lu X, Wang L, Wang H, Zhu Z: MiR-25 regulates apoptosis by targeting Bim in human ovarian cancer. Oncol Rep 2012;27:594-598. 


\section{Cellular Physiology Cell Physiol Biochem 2016;39:1716-1722 and Biochemistry Published online: September 19, $2016 \begin{aligned} & \text { DOI: 10.1159/000447872 } 2016 \text { The Author(s). Published by S. Karger AG, Basel } \\ & \text { www.karger.com/cpb }\end{aligned}$ \\ Deng et al.: MiR-25 for Pancreatic Cancer Diagnosis}

12 Chen C, Ridzon DA, Broomer AJ, Zhou Z, Lee DH, Nguyen JT, Barbisin M, Xu NL, Mahuvakar VR, Andersen MR, Lao KQ Livak KJ, Guegler KJ: Real-time quantification of microRNAs by stem-loop RT-PCR. Nucleic Acids Res 2005;33:e179.

13 Tang F, Hajkova P, Barton SC, Lao K, Surani MA: MicroRNA expression profiling of single whole embryonic stem cells. Nucleic Acids Res 2006;34:e9.

14 Hayes J, Peruzzi PP, Lawler S: MicroRNAs in cancer: biomarkers, functions and therapy. Trends Mol Med 2014;20:460-469.

15 Sun XJ, Liu BY, Yan S, Jiang TH, Cheng HQ, Jiang HS, Cao Y, Mao AW: MicroRNA-29a Promotes Pancreatic Cancer Growth by Inhibiting Tristetraprolin. Cell Physiol Biochem 2015;37:707-718.

16 Song B, Zheng K, Ma H, Liu A, Jing W, Shao C, Li G, Jin G: miR-429 determines poor outcome and inhibits pancreatic ductal adenocarcinoma growth by targeting TBK1. Cell Physiol Biochem 2015;35:1846-1856.

17 Song B, Zhang C, Li G, Jin G, Liu C: MiR-940 inhibited pancreatic ductal adenocarcinoma growth by targeting MyD88. Cell Physiol Biochem 2015;35:1167-1177.

18 Song W, Li Q, Wang L, Wang L: Modulation of FoxO1 expression by miR-21 to promote growth of pancreatic ductal adenocarcinoma. Cell Physiol Biochem 2015;35:184-190.

19 Zhang J, Sun Q Zhang Z, Ge S, Han ZG, Chen WT: Loss of microRNA-143/145 disturbs cellular growth and apoptosis of human epithelial cancers by impairing the MDM2-p53 feedback loop. Oncogene 2013;32:6169.

20 Jang JY, Lee YS, Jeon YK, Lee K, Jang JJ, Kim CW: ANT2 suppression by shRNA restores miR-636 expression, thereby downregulating Ras and inhibiting tumorigenesis of hepatocellular carcinoma. Exp Mol Med 2013;45:e3.

21 Villarroel MC, Rajeshkumar NV, Garrido-Laguna I, De Jesus-Acosta A, Jones S, Maitra A, Hruban RH, Eshleman JR, Klein A, Laheru D, Donehower R, Hidalgo M: Personalizing cancer treatment in the age of global genomic analyses: PALB2 gene mutations and the response to DNA damaging agents in pancreatic cancer. Mol Cancer Ther 2011;10:3-8.

22 Chen F, Hu SJ: Effect of microRNA-34a in cell cycle, differentiation, and apoptosis: a review. J Biochem Mol Toxicol 2012;26:79-86.

23 Jia CY, Li HH, Zhu XC, Dong YW, Fu D, Zhao QL, Wu W, Wu XZ: MiR-223 suppresses cell proliferation by targeting IGF-1R. PLoS One 2011;6:e27008.

24 Raver-Shapira N, Marciano E, Meiri E, Spector Y, Rosenfeld N, Moskovits N, Bentwich Z, Oren M: Transcriptional activation of miR-34a contributes to p53-mediated apoptosis. Mol Cell 2007;26:731-743.

25 Schonleben F, Qiu WL, Ciau NT: PIK-3CA mutations in intraductal papillary mucinous neoplasm/carcinoma of the pancreas. Clin Cancer Res 2006;12:3851-3855.

26 Yu J, Li A, Hong SM, Hruban RH, Goggins M: MicroRNA alterations of pancreatic intraepithelial neoplasias. Clin Cancer Res 2012;18:981-992.

27 Ho AS, Huang X, Cao H, Christman-Skieller C, Bennewith K, Le QT, Koong AC: Circulating miR-210 as a novel hypoxia marker in pancreatic cancer. Transl Oncol 2010;3:109-113.

28 Dai X, Pang W, Zhou Y, Yao W, Xia L, Wang C, Chen X, Zen K, Zhang CY, Yuan Y: Altered profile of serum microRNAs in pancreatic cancer-associated new-onset diabetes mellitus. J Diabetes 2016;8:422-433.

29 Ballehaninna UK, Chamberlain RS: The clinical utility of serum CA 19-9 in the diagnosis, prognosis and management of pancreatic adenocarcinoma: An evidence based appraisal. J Gastrointest Oncol 2012;3:105119.

30 Goldstein MJ, Mitchell EP: Carcinoembryonic antigen in the staging and follow-up of patients with colorectal cancer. Cancer Invest 2005;23:338-351.

31 Kennedy BK, Smith ED, Kaeberlein M: The enigmatic role of Sir2 in aging. Cell 2005;123:548-550. 